\title{
Integration of PDM and ERP systems within a unified information space of an enterprise
}

\author{
Andrey Vladimirovich Ostroukh ${ }^{1}$, Dmitry Olegovich Gusenitsa ${ }^{2}$, \\ Valentina Borisovna Golubkova ${ }^{3}$, Petr FrancevichYurchik ${ }^{4}$ \\ ${ }^{I}$ Doctor of Technical Sciences, Professor, Department of «Automated Control Systems». State Technical \\ University -MADI, Moscow, Russian Federation, \\ ${ }^{2}$ Post-graduate, Department of «Automated Control Systems». State Technical University -MADI, Moscow, \\ Russian Federation, \\ ${ }^{3}$ Ph. D., Associate Professor, Department of «Automated Control Systems». State Technical University -MADI, \\ Moscow, Russian Federation \\ ${ }^{4}$ Doctor of Technical Sciences, Professor, Department of «Automated Control Systems». State Technical \\ University -MADI, Moscow, Russian Federation
}

\begin{abstract}
This article focuses on the research on the complex processes of joint integration of PDM and ERP systems. The relevance of introducing an integrated system within a single information space is justified. The main challenges of systems integration under a unified automation approach are described, including production planning and better management of production data. To successfully solve such problems ERP system needs to operate a certain amount of reference data, without which the production plan will be ineffective or impossible. Due to the fact that such data is often generated and stored in the product data management systems, it becomes necessary to provide data exchange between ERP and PDM systems. A number of key issues relating to the development and establishment of systems are determined. The functions of ERP and PDM systems that require a creation of an interaction interface between them are allocated and described. In conclusion, the positive trends, achievable through integration are reviewed.

Keywords:-integration, Enterprise Resource Planning (ERP), Product Data Management (PDM), Unified Information Space (UIS), Continuous Acquisition and Life-cycle Support (CALS).
\end{abstract}

\section{INTRODUCTION}

Within unified information space ERP and PDM systems are considered tools that perform different tasks, but at the same time complementing each other's functions. PDM system is designed to manage the manufacturing of the product from the creation of its initial documentation to its release date. ERP system in turn uses the information about the product obtained using PDM system, to provide information support to the enterprise management of production and financial resources [1,2].

Joint use of these systems provides the organization with complete control over its production processes. Due to their integration, the latest product data becomes available to the users immediately and it can also be used by all the necessary company departments in order to ensure a more effective production resources planning, which is especially important in modern highly competitive environment, when the rate of development of new products is one of the most important elements of the enterprise success.

That is why the leading developers of ERP systems are now paying increasing attention to integration with PDM systems in order to provide ERP with constantly updated normative and engineering information significantly reduce data redundancy and maintain its integrity [3].

\section{Relevance of Integration Within the Framework of UIS}

The purpose of complex integration of ERP and PDM is to achieve maximum transparency in the management of the enterprises production and financial data [4,5]. A uniform approach to the automation process will allow users to control the resource spending, plan production and generate a list of products and their cost, all in a single information space.

Advantages of this method compared to using individual solutions for each production task are:

- data has to be written only into one system due to the unified information space, reducing the likelihood of discrepancies in the information because of different sources;

- exclusion of data re-entry system users (information is entered into the system only once)

- eliminating fragmentation of information flows in the enterprise;

- all changes to date are carried out through the system and update automatically. 
Briefly summarizing, the integration of PDM and ERP systems greatly simplifies the task of tracking and maintaining the relevance of information by eliminating double data entry, synchronization of document management and ensuring high-quality data exchange between system components in real-time [6].

\section{Integration Tasks}

Successful integration of PDM and ERP in the UIS and its introduction to the enterprise depends on the quality of the business models, as well as transparency and effective management of business processes throughout the enterprise. Another key role is played by qualified personnel and minimizing waste [7]. All employees and departments of the enterprise should be motivated to work with a complex system in real time, which creates a problem of training all employees to work with computer systems.

The main task is to ensure the integration of production processes of the enterprise with the PDMsupport system before its integration with the ERP, due to the fact that in order to achieve effective management of product data, the information must first be developed in the PDM system. To simplify the integration of software components in the system, selected UIS software products should be easily combined with each other using a common database system (Figure 1).

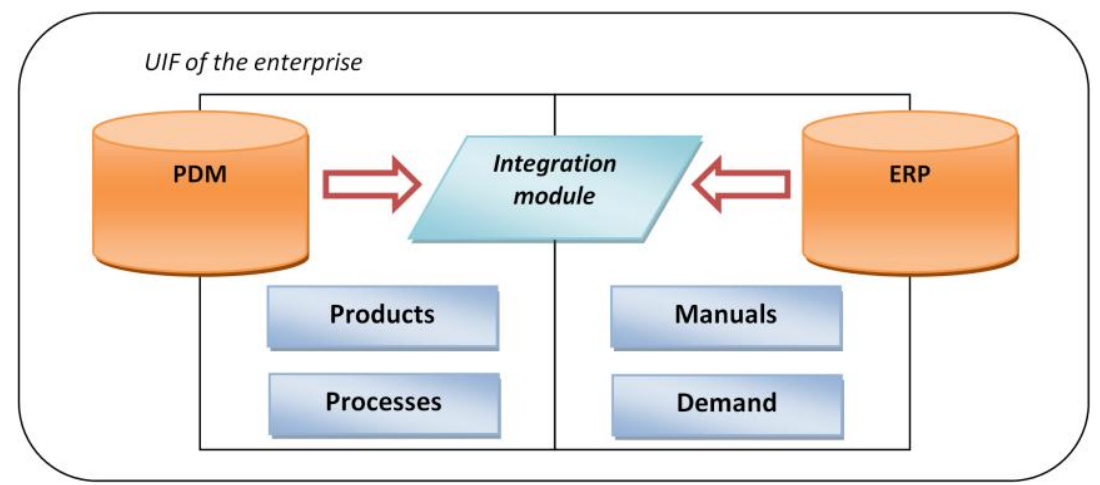

Figure 1.Integration framework of the PDM and ERP systems in the UIS

Integration of the two systems may cause a number of problems:

- production processes of the enterprise are associated with an outdated PDM-system;

- incomplete interaction interfaces of the selected software, which complicates their integration with external systems;

- enterprise uses strictly specialized CAD-systems that do not support software integration among themselves;

- inhomogeneous storage structures of manufacturing information;

- the need to maintain simultaneous work of two systems in real time.

Technical problems associated with different types of information exchange and data formats between ERP and PDM systems are usually solved by developing modules interaction between them [8]. At the same time it is necessary to streamline and automate all data storage involved in the production process to create a reference database for PDM system, eliminating and correcting all the inaccurate information, accounting of materials, components and technological routes. The result of the development would be a constantly updated electronic archive of design and technological documentation.

Table 1 lists the functions of PDM and ERP systems that require the creation of data exchange modules when they are integrated. To achieve this, these functions are broken down into components, and an interaction interface is developed between them.

Table 1. Interacting functions of ERP and PDM systems

\begin{tabular}{|l|l|}
\hline PDM & ERP \\
\hline Document management & Electronic documents \\
\hline Manufacturing process management & Production planning \\
\hline Data access and storage & Information support \\
\hline Management and classification of components & Resource management \\
\hline
\end{tabular}

\section{Operation}

An important feature of the integrated system is its ability to function in real time. This implies instantaneous exchange of information between PDM and ERP when a change of the data version occurs, as opposed to the more common method of transferring data manually at regular intervals [9]. 


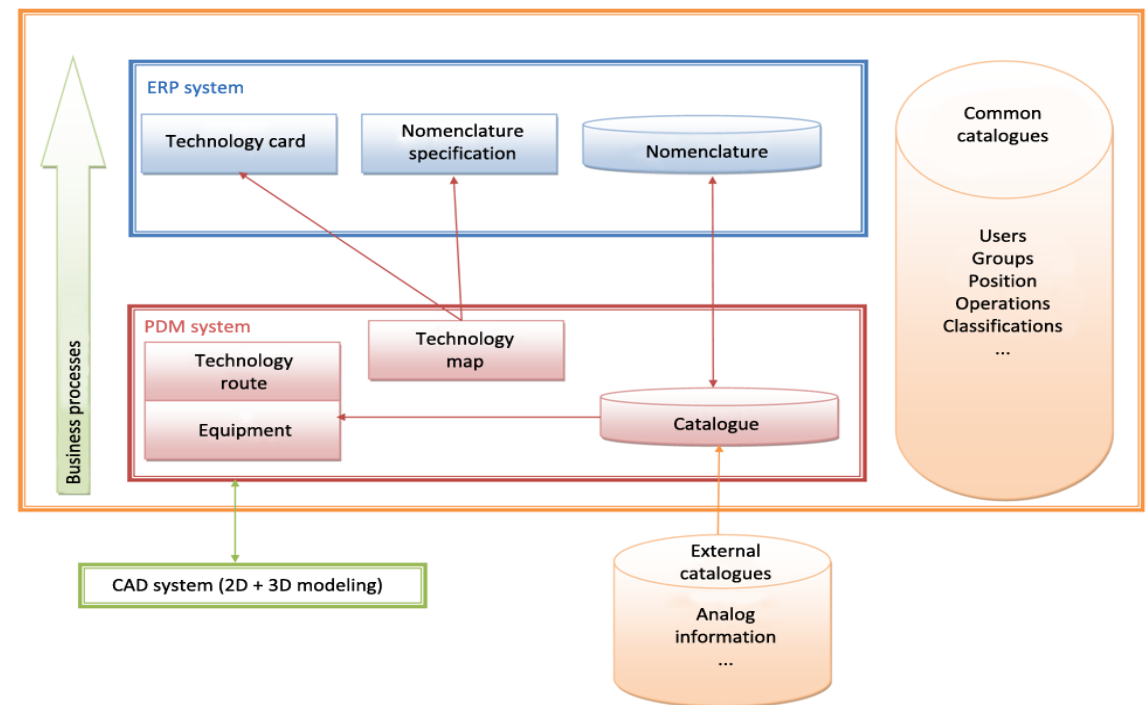

Figure 2. Functions of ERP and PDM

All that is needed for production planning (reference materials and components, the composition of products, processing routes and operations) is automatically transferred in one direction - from the PDM system to ERP system (Figure 2). Data from the PDM system is retrieved into export files, then while passing through integration module it is converted into a format understandable by the ERP system, and after removing the redundant information is imported into ERP. ERP system passes reference materials for equipment and units of measurement in the reverse direction to the PDM system, maintaining synchronization of information between them.

Implementation and use of integrated PDM and ERP systems allows creation and maintaining a unified information space of the enterprise providing implementation of the CALS concept, giving users the ability to manage a closed production cycle, which includes the preparation, planning and production management [10].

\section{Conclusion}

Due to the fact that after the integration of the systems all the products are manufactured according to strict technical processes that use the most recent version of documentation, most of the errors associated with the use of outdated information are eliminated, improving the quality of products. A key outcome of the integration and implementation of ERP and PDM in the UIS is the transparency of information processes in the enterprise. All relevant production documentation is kept in the system that allows users to view and analyze any process and order. The system also provides enterprise managers with constant informational support in the aspects of products price formation and control of enterprise resources.

\section{REFERENCES}

[1] Yurchik P.F., Golubkova P.F., Gromova K.N., Gusenitsa D.O. Use of automated system on PDM platform to maintain the operability of conference hall equipment.In the World of Scientific Discoveries. 2012. №12.

[2] Yurchik P.F., Gusenitsa D.O., Golubkova P.F. Increasing the efficiency of decision support systems through integration of applied information systems. Automation and Control in Technical Systems. 2013. No 4.1. DOI: 10.12731/2306-1561-2013-4-11.

[3] Goryachev S.A., Saakyan I.E., Makarenko L.F., Mazurenko S.V. The role of electronic document automation in management of the enterprise. Innovative methods of automation of technological processes and production: MADI collection of scientific papers. 2008. pp. 103-107.

[4] Sokol A.A., Zamytskikh P.V. Electronic documents synchronization technology. Flow control methods in transport systems: MADI collection of scientific papers. 2009. pp. 95-98.

[5] Sokol A.A., Zamytskikh P.V. Approaches to modeling of automated document management systems of industrial enterprises. Simulationmodelingofcontrol systems. Moscow. MADI. 2012. pp. 104-106.

[6] Nickolayev A.B., Ostroukh A.V., Zamytskikh P.V., Gubanov A.I. Automated system of oil quantity and quality indexes estimation // EUROPEAN JOURNAL OF NATURAL HISTORY. - 2011. - № 3 - pp. 96-98.

[7] Garlan D., Perry D.E. IEEE Transactions on Software Engineering. - Vol. 21, No.4, 1995. -pp.269-274.

[8] Zamytskikh P.V. New Approaches to the Choice of Architecture for a Supervisory System of Gaz Transportation / Bogdanov N.K., Zamytskikh P.V., Khadeev A.S. // Science Journal of Transportation Especial Issue No. 04, International cooperation Journals MADI - SWJTU - UTC (Moscow - Chengdu - Hanoi), 2012. - pp. 61-64.

[9] Moskalev A.G. Using of PDM-systems Support to Product Development Process / Yurchik P.F., Komkov F.S., Moskalev A.G. // Information and Telecommunication Technologies in Intelligent Systems: Proceedings of Sixth International Conference Crete, Greece, 2008. - pp. 60-61.

[10] Moskalev A.G. Construction of a generalized functioning model for sub-systems complex computer-aided system for manufacturing business (by the example of logistic subsystem) / Information and telecommunication technologies in intelligent system. Proceedings of Fourth International Conference Catania, Italy // International Academy of Information, Mallorca, Spain, 2006. - pp. 62-64. 